\section{TRECOS MÓVEIS: A MOBILIDADE EM POTÊNCIA E O NOVO PAPEL SOCIAL DOS OBJETOS NA PUBLICIDADE DAS MARCAS}

\author{
Mobile stuff: mobility potential and the new role of \\ objects in brand advertising
}
Cosas móviles: potencial de movilidad y lo nuevo rol social de los objetos en la publicidad de marca

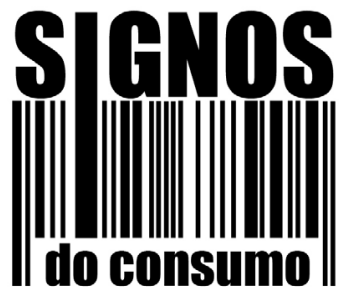

artigo

\author{
Maria Alice de Faria Nogueira \\ Universidade Estácio de Sá, Rio de Janeiro, Brasil \\ Doutora em História, Política e Bens Culturais pela Fundação Getúlio Vargas (FGV) e Mestre em \\ Comunicação Social pela PUC-Rio. Membro dos Grupos de Pesquisa Mobilidades: teorias, temas e \\ métodos (MTTM) e Retórica do Consumo (ReC). E-mail: prof.maria.alice@gmail.com
}

RESUMO Uma nova condição social que evidencia a propensão à mobilidade da vida contemporânea faz emergir os "trecos móveis" que oferecem, facilitam ou dão acesso à mobilidade em potência necessária à vida em constante movimento. O objetivo desse artigo é refletir sobre a emergência desse novo papel social dos objetos e discutir a maneira com que esse fenômeno é midiatizado na publicidade de marcas. Para tal tarefa, colocamos em diálogo os autores John Urry, Daniel Miller e Arjun Appadurai, além de apresentar exemplos de campanhas que relacionam o discurso da mobilidade à diferentes categorias de objetos.

PALAVRAS-CHAVE Trecos móveis, Potencial de movimento, Publicidade das marcas.

\begin{abstract}
A new social condition that evidence the propensity to mobility also gives rise to the "mobile stuff" or objects that offer, facilitate, or give access to the mobility potential that individuals need to cope with life on the move. This article aims to reflect on the emergence of this new social role of objects and to discuss the way in which this phenomenon is mediatized in brand advertising. For such purpose, authors such as Jonh Urry, Daniel Miller, and Arjun Appadurai are put in dialogue to analyze some examples of campaigns that relate to the discourse of mobility with different categories of objects.

KEYWORDS Mobile stuff, Mobility Potential, Brand advertising.
\end{abstract}

RESUMEN Una nueva condición social que pone en evidencia la propensión a ser móvil también da lugar a las "cosas móviles" que ofrecen, facilitan o dan acceso al potencial de movilidad que las personas necesitan para vivir la vida en movimiento. El propósito de este artículo es reflexionar sobre el surgimiento de este nuevo rol social de los objetos, así como discutir la forma en que este fenómeno se mediatiza en la publicidad de marca. Para esto, ponemos en diálogo autores como Jonh Urry, Daniel Miller y Arjun Appadurai, además de presentar algunos ejemplos de campañas que relacionan el discurso de la movilidad con distintas categorías de objetos.

PALABRAS CLAVE Cosas móviles, Potencial de movilidad, Publicidad de marca. 


\section{INTRODUÇÃO}

Um carro que telefona e conecta as pessoas. Um desodorante que ativa suas funções com base no movimento do(a) usuário(a). A maionese com sabor de cidade ou um perfume com o odor de cidade. O curso de inglês que move - ou que pode mover - o estudante, social ou profissionalmente. A marca de joia que afirma a feminilidade pelo movimento. A marca de uísque que globalmente afirma seu posicionamento ao convocar seus consumidores a "continuarem caminhando" ou, simbolicamente, seguindo em frente. Ou ainda a campanha da clínica de reabilitação que pede aos seus clientes que doem mobilidade. Esses são alguns exemplos de produtos e de serviços, os quais optaram por divulgar seus benefícios utilizando o discurso do movimento (físico ou geográfico) e da mobilidade (social, virtual ou imaginativa) como argumento central de suas estratégias de comunicação.

Se considerarmos os estudos e teorias relacionadas à atividade do consumo, pensado aqui como busca, aquisição, uso e descarte dos bens (BAUDRILLARD, 1970), não é estranho perceber, nos exemplos citados, que a principal argumentação do discurso publicitário não reside na utilidade funcional do bem e de seus benefícios intrínsecos, como o deslocamento seguro, no caso do carro, ou a higiene pessoal, no caso do desodorante. Como afirma Sahlins (2003), entre outros autores do campo dos estudos do consumo, na contemporaneidade as motivações para aquisição de algo ultrapassam seu valor de uso enquanto objeto e solucionam carências relacionadas às dimensões simbólica e subjetiva, postas em evidência pelas atividades da comunicação publicitária.

No entanto, o que chama a atenção nos exemplos citados é o fato de que, por mais diferentes que sejam, se pensarmos suas categorias de vendas, mercados de atuação e público-alvo, os produtos e serviços em questão escolheram as práticas da mobilidade real ou potencial como argumento de venda, independentemente de terem ou não a capacidade de se moverem e/ou darem suporte à movimentação de outrem.

Considerando a perspectiva teórica de que publicidade é uma atividade que dialoga com a cultura de seu tempo e lugar, cujo discurso é pensado como uma área de transferência de significados culturais (MCCRACKEN, 2003), é interessante notarmos o protagonismo da cultura da mobilidade (URRY, 2003) no discurso publicitário contemporâneo, que faz que marcas de joias, carros, desodorante, ensino, perfumes, maionese e uísque, além de marcas de celular, jornais e revistas, seguro de vida, bancos, clínicas de reabilitação e fisioterapia etc. -tenham alguma coisa em comum.

A percepção dessa tendência discursiva de relacionar mercadorias de diferentes segmentos a um mesmo argumento de vendas, no caso, o benefício da mobilidade real ou em potência, foi o ponto de partida do estudo, aprofundado na pesquisa de tese da autora (NOGUEIRA, 2015), do qual esse texto é um recorte. Dessa forma, esse artigo tem como objetivo colocar em evidência a propensão à mobilidade da vida contemporânea midiatizada na publicidade das marcas e refletir, com base nessa constatação, sobre duas questões que se mostram importantes na análise: a própria cultura da mobilidade, tratada, aqui, sob a perspectiva do Paradigma das Novas Mobilidades (URRY; SHELLER, 2006) que, ante seu protagonismo na contemporaneidade social, móvel e de risco, tem permeado o discurso publicitário; e, por conseguinte, o novo papel social dos objetos que se tornam "trecos móveis", no sentido em que, pela sua (i)materialidade (APPADURAI, 1986; MILLER, 2014), passam a 
ser apresentados enquanto artefatos que oferecem, facilitam, dão acesso ou bloqueiam a mobilidade em potência necessária à vida cotidiana do indivíduo contemporâneo, que se encontra em constante movimento.

Esse artigo está dividido em duas partes: na primeira, será tratado o entrelaçamento da mobilidade, da objetificação das coisas e as representações do consumo no discurso publicitário a partir de uma triangulação teórica entre John Urry, Daniel Miller e Arjun Appadurai, com base em suas obras Mobilities (2007), Trecos, troços e coisas (2014) e $A$ vida social dos objetos (1986) respectivamente. Em um segundo momento, a partir de anúncios e comerciais veiculados entre 2011 e 2017, serão apresentados exemplos da articulação entre as novas condições sociais de mobilidade dos indivíduos e o novo papel social dos objetos e sua presença na comunicação publicitária das marcas.

As campanhas analisadas fazem parte do acervo pessoal da autora, que começou a ser organizado durante o período do doutorado (2011-2015). O método utilizado na seleção das peças foi a "amostra por conveniência" que, segundo Malhotra (2011, p. 275), tem como objetivo "gerar ideias, adquirir novas compreensões e desenvolver hipóteses”. Para oferecer uma visão mais abrangente da proposta do artigo, mesmo conhecendo a limitação do método no que se refere à generalização da ideia, foram selecionadas quatro peças, com base nos seguintes critérios: diferentes categorias de produtos e serviços; variados mercados e públicos-alvo; oferecimento de diversos tipos de mobilidade (física, virtual, social e informacional) no discurso de transformação dos referidos objetos em "trecos móveis".

\section{A MOBILIDADE EM POTÊNCIA E A VIDA EM MOVIMENTO}

Ao afirmar que a cultura da mobilidade entrelaça questões tecnológicas, sociais e antropológicas, Lemos (2009, p. 28) aponta para o fato de que, no caso específico da comunicação, mobilidade é tema central, já que "comunicar é fazer mover signos, mensagens e informações, sendo toda mídia (dispositivos, ambientes e processos) estratégias para transportar mensagens que afetam nossa relação com o tempo e o espaço". É na identificação do fenômeno social da mobilidade - i.e., o movimento positivamente valorado, em articulação com a comunicação, com foco no discurso publicitário - que reside o ponto que o artigo traz à luz. Quando os deslocamentos físicos, geográficos, virtuais ou imaginativos de pessoas, bens e informação tomam a frente nas relações e alteram radicalmente os modos de vida em todas as esferas - social, cultural, política e econômica -, um diferente cenário social se apresenta e demanda novos objetos que deem conta das novas possibilidades e experiências de (i)mobilidade dos sujeitos em sua vida cotidiana, assim como criam novos discursos que dão pistas da experiência de vida e da importância da cultura material da contemporaneidade.

Mesmo tratando das questões das mobilidades na contemporaneidade, é importante pensar historicamente como a mobilidade se tornou condição de vida. De acordo com Simmel (2005), foi na virada entre os séculos XIX e XX que a onipresença da técnica aplicada tanto aos transportes quanto à comunicação alterou de forma radical a maneira como os indivíduos experimentavam suas relações com o território, com objetos, com a família e seus grupos de pertença, enfim, com o tempo e com o espaço que não somente habitavam, mas, passaram a circular com mais velocidade e técnica. 
Nesse cenário de novos estímulos e de crescente circulação, houve o desenvolvimento de uma alta subjetividade, no sentido de exaltar a diferença individual no meio do todo social. Nesse sentido, a vida na cidade, sua pressa, velocidade e fragmentação geram um poderoso sistema objetivo que, por um lado, está preocupado com a manutenção das regras e formalidades das relações à distância; assim como, por outro, faz surgir um variado leque de subjetividades individuais, baseado em uma perversa combinação entre a sistematização da vida e a personalização do indivíduo na modernidade (Ibidem). No que tange à personalização, uma das maneiras encontradas pelos indivíduos para marcarem suas diferenças e imporem suas subjetividades em meio à multidão das cidades foi a apropriação criativa dos objetos. A questão do consumo dos objetos será melhor tratada adiante, mas é interessante colocar que foi nesse cenário de metropolização das cidades e de uma nova condição de vida que o consumo se afirmou como uma prática de formação de subjetividades, construídas para darem conta de experiência de vida social mais veloz, fluida e móvel que naquele momento começava. De acordo com Kesselring (2008, p. 81), “a mobilidade é o princípio fundamental da modernidade".

Foi no sentido de pensar a vida social a partir do movimento, que Urry e Sheller (2006) propuseram um Paradigma das Novas Mobilidades (PNM), por meio do qual as Ciências Sociais se tornariam movement-driven. Nesse sentido, este giro epistemológico

Permite que o mundo social seja teorizado como uma ampla gama de práticas sociais, econômicas e políticas, assim como de ideologias, infraestruturas que envolvem, implicam ou cerceiam variados tipos de movimento de pessoas, de ideias, de informação e de objetos. (URRY, 2007, p. 18)

A questão dos diferentes tipos de mobilidades já foi tratada em textos anteriores (NOGUEIRA 2015; 2016), mas é importante ressaltar que cada mobilidade pressupõe um sistema, ou variados sistemas interligados, constituídos, entre outros arranjos, por conjuntos - ou híbridos de pessoas e máquinas interconectados no tempo e no espaço de forma múltipla e complexa, e que não evoluem de maneira linear. Esses sistemas têm como objetivo colocar o mundo em movimento de forma previsível e sem riscos: eles proporcionam espaços de antecipação em que a viagem pode ser feita, a mensagem pode ser veiculada e o objeto pode circular em uma repetição previsível e relativamente sem riscos.

Neste sentido, o PNM enfatiza a importância do mundo sociomaterial e realça as relações entre a ação humana e os objetos que formam os híbridos citados. Urry (2007, p. 45) afirma que a vida nunca foi puramente humana e que, portanto, a experiência de humanidade não pode ser vivida sem a interdependência do sujeito com seu mundo material. "O poder dos humanos é sempre aumentado pelo variado mundo material das roupas, das ferramentas, dos objetos, dos caminhos, dos edifícios etc.”, afirma o autor, reforçando a ideia de que os objetos empoderam o ser humano.

Nessa perspectiva, a vida social é fundamentalmente heterogênea e sua heterogeneidade é constituída por uma série de objetos, incluindo a natureza e a tecnologia, que movem ou bloqueiam o movimento de outros objetos, pessoas e informação. Segundo o autor, sujeitos e objetos estão/são agrupados e reagrupados em diferentes arranjos, nas mais 
diversas condições espaçotemporais. Estas duas entidades combinadas produzem e experimentam as práticas sociais no interior de uma mobilidade descontínua, cujo próprio movimento pode oferecer fluidez ou resistência para outros bens em movimento.

Pensar os bens como objetos que possuem, intrínseco à sua existência, o atributo da mobilidade confere mudanças à maneira pela qual pensamos como a vida cotidianamente se organiza. Não somente porque deixa claro que o mundo socio-material contemporâneo é como um grande conglomerado de sistemas em rede complexos e interdependentes que suportam a vida em movimento, o que só fortalece a ideia da mobilidade como um paradigma na análise social, mas também porque esta classificação traz à tona uma enorme variação de possibilidades e da disponibilidade, assim como da potencialidade e da força de cada objeto, em relação ao ambiente e ao seu consumo e/ou seu uso pelos indivíduos.

Neste ponto, evocamos Miller (2014) e sua Teoria de Objetificação, segundo a qual todo e qualquer objeto possui a capacidade de marcar o ambiente, firmar identidades e determinar ações e comportamentos diante das situações que a vida impõe. A cultura material surge por meio de uma presença constante, sólida e forte que constrói o cenário em que as sociabilidades se dão. Emolduram a existência de tal modo que o indivíduo não percebe sua presença, tornando impossível escapar de seu afeto. Para Miller (2014), assim como para Urry (2007), a cultura material não se restringe à sua materialidade ou à sua tangibilidade. Pelo contrário: pela sua intangibilidade os objetos determinam o que ocorre à medida que estamos inconscientes da capacidade que têm de fazê-lo (MILLER, 2014).

Ao pensar o objeto pela sua intangibilidade e imaterialidade, Miller lança mão da noção de "treco" (stuff), que incluiria todo tipo de coisas, "corpos, streaming, vídeos, sonhos, cidades, sensações, derivativos, ideologias, paisagens, deteriorações, filosofias, inclusive, a nós mesmos”. “Trecos” são ubíquos e problemáticos e essa condição de existência implica, nos termos de Miller (2014), que "grande parte do que nos torna humanos existe não por meio da consciência ou do nosso corpo, mas como um ambiente exterior que nos habitua e incita". Em resumo, nos parece possível juntar a ideia de "treco", de Miller, à ideia de "híbridos”, de Urry. Ambos realçam as relações entre a ação humana e os objetos e reafirmam a noção de que não há oposição, vigente no senso comum, entre pessoa e coisa, animado e inanimado, sujeito e objeto.

Com este conjunto entre o homem e a máquina, a vida social, de trabalho ou em família, a educação ou a atuação política podem ser experimentadas com base em modos de presença ou de ausência que dependem, em parte, de múltiplas tecnologias de viagem e de comunicação que movem objetos, pessoas, ideias e imagens através de diferentes distâncias e condições espaçotemporais. A movimentação neste cenário ainda se vê potencializada por novas combinações entre indivíduos e objetos e entre estes híbridos e os sistemas, em variadas e diferentes relações de acoplagem que demandam novos sistemas, que se (re)fazem e se (re)organizam enquanto estão "intrainteragindo", maximizando ainda mais a velocidade da técnica e a fluidez do cenário. A questão que aqui se coloca é que os intensos fluxos de mobilidades exigem novas capacidades, habilidades e potencialidades dos sujeitos, assim como dos objetos, que passam a ser desenhados de forma a conter a "motilidade" em sua (i)materialidade. Segundo Kaufmann (2002, p. 37), 
motilidade é referente à "capacidade de a pessoa ser móvel ou, mais precisamente, a maneira com que o indivíduo se apropria do que é possível no domínio da mobilidade e usa esse potencial em suas atividades”. Entendida, dessa forma, como mobilidade em potência, a motilidade presente nos objetos será empenhada para tornar a vida do sujeito mais ou menos móvel, sendo a maneira de uso, a ocasião e as motivações decididas em função das escolhas, estilos e projetos de vida individuais.

Nesse sentido, e com base na noção de stuff de Miller, somada às novas condições de vida na contemporaneidade móvel, os objetos se tornam "trecos móveis", isto é, objetos que carregam em si a mobilidade em potência para dar conta da vida contemporânea, que é, em grande medida, experimentada em movimento. A emergência dos "trecos móveis" e da potência de mobilidade que os objetos passam a emanar coloca em evidência uma das cinco mobilidades propostas por Urry (2007, p. 50), a saber, o "movimento dos objetos".

A ideia de destacar o movimento dos objetos diz respeito ao entendimento de que, por estar vinculada diretamente às práticas de consumo, a publicidade é parte integrante e fundamental da circulação dos bens. Entre o produtor e o varejo há o momento em que o produto ganha vida e torna-se algo desejável e passível de troca, nos termos de Appadurai (1986), torna-se, então, commodity ou mercadoria. De acordo com o autor, todos os objetos possuem "vida social" a partir do momento em que sofrem ressignificações constantes, conforme desenham suas trajetórias no tempo e no espaço. Esses novos significados são firmados com base em contextos econômicos, políticos, sociais, culturais e religiosos e são impostos pelos atores sociais que definem, desta maneira, a trajetória social dos bens. Portanto, é baseado na sua trajetória social e na sua capacidade de mobilidade significativa que o objeto sofre o processo de "mercadorização" ou "desmercadorização”, isto é, torna-se mercadoria ou deixa de sê-lo, dependendo de contextos socioculturais que acentuam seus significados e seu valor de troca. Nesse sentido, a presença da ordem cultural é decisiva nas situações de troca e ultrapassa a prevalência do utilitarismo e da razão prática que domina as mercadorias pela ótica da administração e da economia, como já citado na introdução desse artigo (SAHLINS, 2003).

Appadurai (1986) propõe uma nova direção neste ponto de vista que vincula a valorização dos objetos a certas condições, sob as quais circulam, isto é, certos "regimes de valor" determinados pela cultura e, por isso, inseridos em tempo e espaço próprios. Novamente, o autor enfatiza que o que valorizaria o objeto não é somente o que nos mostram as transações, atribuições ou motivações humanas, mas sua circulação, trajetória e biografia social. Sobre esse aspecto, então, na vida social das coisas, o valor econômico de uso da mercadoria é menos determinante do que a trajetória social e cultural feita pelo objeto, desde sua produção até sua troca, distribuição, consumo e descarte.

Para compreender melhor o que os objetos nos dizem, assim como seu significado histórico, é importante que esta trajetória seja acompanhada. A interpretação das transações e dos cálculos humanos que animam as coisas somente poderá ser analisada por meio do estudo das trajetórias cultural e comercial que mercadorizam o objeto. E, neste ponto, é possível retornar à questão da publicidade como parte do movimento dos objetos, como o "local" no qual o novo papel social do objeto como treco móvel passa a ser discursivamente apresentado. 


\section{TRECOS MÓVEIS: NOVO PAPEL SOCIAL DOS OBJETOS NA COMUNICAÇÃO PUBLICITÁRIA DAS MARCAS}

Como já mencionado, por apresentarem significações, ancoradas na cultura, que vão além de suas características utilitárias e de seus valores comerciais, os bens passam a acompanhar as mudanças da sociedade e tornam-se repositórios de significados em trânsito porque validados pela prática humana e pelas ações cotidianas do indivíduo na sociedade. A qualidade móvel dos significados carregados pelos bens obedece, segundo McCracken (2003), a uma trajetória de transferência em dois tempos: do mundo culturalmente constituído para os bens de consumo e dos bens para o consumidor individual. Como atividade que dá visibilidade ao consumo, a publicidade se estabelece como área de transferência simbólica na qual a cultura de referência, i.e., a cultura da mobilidade, é reafirmada. Dessa forma, a produção de bens aparece como uma maneira de materializar os valores sociais e os princípios culturais vigentes e as suas distinções, fazendo que, na contemporaneidade, as motivações e as práticas de consumo tornem-se tradução de um projeto de vida que idealizado se realiza, ressignificado, nos objetos (BAUDRILLARD, 1970).

Neste ponto retornamos à ideia principal deste artigo, que traz à tona a ideia de que, na contemporaneidade mobilizada física, geográfica, virtual e imaginativamente, produtos, serviços e marcas, independentemente de seu mercado de atuação, público-alvo ou características, tornam-se trecos móveis, isto é, assumem um novo papel social de algo que oferece, suporta, facilita ou dá acesso à mobilidade em potência que os indivíduos contemporâneos precisam para dar conta da vida em movimento. Como já mencionado, ao adquirir um treco, os indivíduos adquirem a motilidade necessária para escapar dos riscos e vivenciar certa estabilidade no cenário social fluido contemporâneo. É exatamente nesta parceria que reside a força: em cada objeto - tangível ou não, como a tecnologia, ou ainda algo constitutivo da natureza, além da própria humanidade - existe certo potencial de uso, que será ou não transformado em movimento pelos indivíduos, com base em seus estilos e projetos de vida.

Para atender a demanda de um público que está cada dia mais em circulação, a publicidade eleva o potencial de movimento de cada treco em seu principal argumento discursivo. Sob este aspecto, a publicidade não venderia mais somente a razão prática para o uso do bem, como em uma sociedade industrial; ou não venderia mais somente a identidade ou status conseguidos pela aquisição do bem, como numa sociedade de consumo; mas, principalmente, venderia a mobilidade, em potência necessária para dar conta da vida em uma sociedade na qual uma cultura da mobilidade se faz presente o tempo todo (NOGUEIRA, 2015; 2016).

A seguir, quatro peças publicitárias serão analisadas e, nelas, o discurso da mobilidade potencial - simbólica, social ou física é elevada ao patamar de benefício do objeto e, a reboque, de principal argumento de vendas ou de engajamento, assim como de reafirmação de posicionamento das marcas, produtos e serviços que se tornaram, dessa forma, trecos móveis.

O primeiro caso é o da campanha \#nãoaorótulo, da Nextel, de 2016. No caso do comercial em questão, o músico Junior Lima cita alguns dos rótulos sociais com os quais teve que conviver ao longo de sua carreira: "nunca saiu do armário"; "vive à sombra de sua irmã"; entre outros. Ao fim, ele afirma que as escolhas sobre quem ele é ou não é estão em suas mãos. A cena corta para Junior com um Nextel na mão, quando ele 
fala suas últimas palavras: "Nextel, tá nas suas mãos”. O comercial da operadora é um bom exemplo de como a mobilidade em potencial pode servir como uma ferramenta de subjetividade ao se colocar a serviço da pessoa, em um acordo entre o homem e a máquina. O discurso da mobilidade evidencia, inclusive, a individualização da sociedade moderno-contemporânea ao jogar luz nas possibilidades de câmbio de persona, em função das escolhas de consumo dos indivíduos, feitas com base em seus estilos e projetos de vida.

O próximo comercial é o do desodorante Rexona Motionsense, de 2011, que utiliza o discurso da mobilidade para divulgar as propriedades tecnológicas do produto: quanto mais nos mexemos, isto é, quanto mais nos movemos, mais o desodorante libera pequenas partículas que protegem o corpo dos odores da movimentação diária intensa. Em um dos comerciais da campanha global, o movimento é marcado por uma pulseira que acende a cada deslocamento do corpo. Nesse sentido, a pulseira materializa as práticas de mobilidade do target ao longo de suas atividades cotidianas e sinaliza as potencialidades do desodorante. Dessa forma, discursivamente, o potencial de mobilidade do Rexona é utilizado de maneira a minimizar os riscos da circulação física diária: o uso do desodorante despreocupa o(a) usuário(a) de qualquer constrangimento em relação aos cheiros do corpo ao permitir que ele(a) circule com segurança desde o trabalho à balada.

Em uma época em que as relações de vida se dão a distância, incluindo relações pessoais e de trabalho, além de atividades culturais e até mesmo de ativismo político, novas demandas são criadas. A próxima campanha, \#carroconectado, da Volkswagen, de 2016, desloca o discurso do movimento físico do carro para a capacidade do Novo Gol de conectar pessoas. A questão, aqui, é que essa conexão não se dá pelo deslocamento tecnicamente seguro proporcionado pelo automóvel, mas pela mobilidade virtual, que passa a ser um dos principais features do carro. A motilidade desse treco móvel é enfatizada discursivamente quando reforça a ligação entre familiares socialmente distanciados ao colocá-los em contato via bluetooth e telefonia celular, fazendo do Novo Gol parte de um sistema de mobilidade que vai além do deslocamento físico do automóvel. Nesse caso, a publicidade transforma o carro em um dispositivo móvel não por sua capacidade de mover-se, mas por sua potência de conexão virtual, especialmente ao reforçar o hibridismo, isto é, a acoplagem, necessária nessa vida em constante movimento, entre o homem e a máquina.

Para finalizar, em 2017, com apoio da TV Record, a Associação Brasileira Beneficiente de Reabilitação - ABBR, sediada no Rio de Janeiro, lançou a campanha "Doe Mobilidade" para arrecadar dinheiro para a compra de cadeiras de rodas. Segundo o superintendente da ABBR, Robson de Bem, em matéria veiculada na emissora parceira, além da arrecadação, o objetivo da campanha era, por meio da cadeira de rodas, reabilitar o sujeito não só fisicamente, mas emocional, social e profissionalmente. Nesse caso, a mobilidade aparece no discurso de pelo menos duas formas: não só como objeto a ser doado, mas também como potência de qualidade de vida. A cadeira de rodas, nesse caso específico, está inserida em um regime de valor, nos termos de Appadurai (1986), que minimiza seu valor econômico diante de seu valor social e cultural. A potência de mobilidade nesse caso está relacionada ao movimento físico, ao mesmo tempo em que resume, no treco "cadeira de rodas", o conceito de motilidade de Kaufmann (2002), permitindo que o indivíduo se aproprie do que é possível no domínio da mobilidade e utilize esse potencial nas suas atividades cotidianas. 


\section{CONSIDERAÇÕES FINAIS}

A vida contemporânea parece, cada vez mais, seguir pelo caminho do movimento, da circulação e da mobilidade de pessoas, objetos, valores, informações e ideias. A cada dia, diferentes sistemas de lógicos de mobilidade que congregam tecnologia em transportes e em comunicação são desenvolvidos e postos em prática em dimensões que variam de pequenas tarefas domésticas à grandes decisões corporativas globais. Em contrapartida a essa vida mobilizada pela tecnologia, surgem novos objetos, ou trecos móveis, que são valorizados pela sua potência de conexão e de circulação, isto é, pela sua capacidade de colocar em situação de mobilidade ou de imobilidade - virtual, física, geográfica ou imaginativa - os sujeitos contemporâneos.

Nesse sentido, o novo papel social dos objetos seria o de dar suporte, facilitar ou bloquear o movimento, a circulação e a (i)mobilidade cotidiana a partir de regimes de valor e de discursos que reforçam a tendência à mobilidade como argumento na publicidade das marcas, independentemente da categoria de venda, mercado de atuação e públicoalvo. Essa tendência discursiva aponta para uma nova condição social de vida relacionada à cultura da mobilidade, no interior da qual uma cultura material tenta se adaptar às novas condições do ambiente, em um movimento circular, próprio do tema. E, nesse looping perpétuo de (re)configurações, a publicidade segue dando visibilidade ao movimento e ao consumo dos objetos em toda sua potência, não só como atividade comercial e de vendas, mas como espaço de significação, de afirmação de subjetividade e, principalmente, de reafirmação da cultura da mobilidade.

\section{REFERÊNCIAS}

ABBR lança campanha "doe mobilidade" para comprar cadeiras de rodas. [S. l.: s. n.], 2017. 1 vídeo (4 min). Publicado pelo canal ABBR - Associação Brasileira Beneficente de Reabilitação. Disponível em: https://bit.ly/2RiGTWF. Acesso em: 14 maio 2021.

APPADURAI. Arjun. The social life of things: commodities in cultural perspective. Cambridge: Cambridge University Press, 1986. E-book.

BAUDRILLARD, Jean. A sociedade de consumo. Lisboa: Edições 70, 1970.

IRMÃOS| novo gol | vwBrasil. [S. l.: s. n.], 2016. 1 vídeo (1 min). Publicado pelo canal Volkswagen do Brasil. Disponível em: https://bit.ly/3fk3N83. Acesso em: 14 de maio 2021.

KAUFMANN, Vincent. Re-thinking mobility: contemporany sociology. Farnham: Ashgate, 2002.

KESSELRING, Sven. The mobile risk society. In: WEERT, Canzler; KAUFMANN, Vincent; KESSELRING, Sven (ed.). Tracing mobilities: towards a cosmopolitan perspective. Burlington: Ashgate, 2008. p. 77-102.

McCRAKEN, Grant. Cultura e consumo. Rio de Janeiro: Mauad, 2003.

MALHOTRA, Naresh. Pesquisa de Marketing: foco na decisão. São Paulo: Prentice Hall, 2011.

MILLER, Daniel. Trecos, troços e coisas: estudos antropológicos sobre a cultura material. Rio de janeiro: Zahar, 2014. E-book.

NOGUEIRA, Maria Alice de Faria. Mobilidade em potência e discurso publicitário na sociedade contemporânea globalizada: Brasil, 1982-2014. 2015. Tese (Doutorado em História, Política e Bens Culturais) - Fundação Getúlio Vargas, Rio de Janeiro. 2015.

NOGUEIRA, Maria Alice de Faria. Consumo de (i)mobilidade e discurso: a cultura da mobilidade na publicidade das marcas. Comunicação, Mídia e Consumo, São Paulo, v. 13, n. 36, p. 28-49, 2016.

PRIMEIRA-dama Sylvia Jane Crivella é madrinha de campanha para doação de cadeira de rodas. Rio.gov.br, Rio de Janeiro, 17 mar. 2017. Disponível em: https://bit.ly/33HtAS3. Acesso em: 17 maio 2021. 
REXONA com tecnología Motionsense. [S. I.: s. n.], 2014. 1 vídeo (1 min). Publicado pelo canal Rexona Perú. Disponível em: https://www.youtube.com/watch?v=MM8ElefnHNA . Acesso em: 14 maio 2021.

SAHLINS, Marshall. Cultura e razão prática. Rio de Janeiro: Jorge Zahar, 2003.

SHELLER, Mimi; URRY, John. The new mobilities paradigm. Environment and planning A, Lancaster, v. 38, n. 2, p. 207-226, 2006.

SIMMEL, Georg. As grandes cidades e a vida do espírito. Mana, Rio de Janeiro, v. 11, n. 2 , p. 577-591, 2005. Disponível em: https://bit.ly/3bxB3aP. Acesso em: 6 jun. 2020.

URRY, John. Mobile Cultures. Lancaster: Lancaster University, 2003. Disponível em: https://bit.ly/3uTCsjK. Acesso em: 6 jun. 2020.

URRY, John. Mobilities. Cambridge: Polity Press, 2007.

\section{(9)(ब(}

